\title{
Correction to: A DFT study of electronic, vibrational and optical properties of gold clusters
}

\author{
Tahir Iqbal ${ }^{1}$ - Amna Azam ${ }^{1} \cdot$ Abdul Majid $^{1} \cdot$ Maria Zafar $^{1}$ D $\cdot$ Muhammad Shafiq $^{2}$. \\ Sami Ullah ${ }^{3} \cdot$ Mohamed Hussien $^{3}$
}

Published online: 1 March 2022

() The Author(s), under exclusive licence to Springer Science+Business Media, LLC, part of Springer Nature 2022

\section{Correction to: Optical and Quantum Electronics (2022) 54:74 https://doi.org/10.1007/s11082-021-03446-1}

In the original publication of the article the below mentioned reference was published incorrectly and it has been corrected with this Correction.

\section{Reference}

Vishwanathan, K.: Vibrational heat capacity of gold cluster AuN $=14$ at low temperatures. J. Phys. Chem. Biophys. 6(232), 2161-2398 (2016)

Publisher's Note Springer Nature remains neutral with regard to jurisdictional claims in published maps and institutional affiliations.

The original article can be found online at https://doi.org/10.1007/s11082-021-03446-1.

Tahir Iqbal

tiqbal02@qub.ac.uk

$\triangle$ Maria Zafar

maria.zafar76@gmail.com

1 Department of Physics, Faculty of Sciences, University of Gujrat, Hafiz Hayat Campus,

Gujrat 50700, Pakistan

2 Department of Physics, Quaid-i-Azam University, Islamabad 45320, Pakistan

3 Department of Chemistry, College of Science, King Khalid University, P.O.Box 9004, Abha 61413, Saudi Arabia 